\title{
EFEITO DA INCORPORAÇÃO DE CASCA DE CAFÉ NAS PROPRIEDADES FÍSICO-MECÂNICAS DE PAINÉIS AGLOMERADOS DE Eucalyptus urophylla S.T. Blake
}

\author{
Effect of the incorporation of coffee husks on the physico-mechanical properties of \\ Eucalyptus urophylla S.T. Blake particleboards
}

\author{
Rafael Farinassi Mendes', Lourival Marin Mendes ², José Benedito Guimarães Júnior 2, \\ Fábio Akira Mori ${ }^{2}$, Antonia Amanda da Silva César ${ }^{2}$
}

\begin{abstract}
RESUMO
Neste trabalho objetivou-se avaliar a influência da incorporação de casca de café nas propriedades físico-mecânicas de painéis aglomerados produzidos com Eucalyptus urophylla S.T. Blake. Os painéis foram produzidos com incorporação de 25,50 e $75 \%$ de casca de café, em três teores da resina fenol-formaldeído $(6,9$ e $12 \%)$ e $1 \%$ de parafina. A densidade nominal dos painéis foi de $0,7 \mathrm{~g} / \mathrm{cm}^{3}$ e o ciclo de prensagem compreendeu uma pressão de 3,92 $\mathrm{MPa}$ e temperatura de $180^{\circ} \mathrm{C}$ por 8 minutos. Pelos resultados obtidos foi possível observar que: as propriedades físicas dos painéis aglomerados apresentam relação linear decrescente com o aumento do teor de resina, e crescente com a porcentagem de casca de café, apresentando maiores valores de absorção de água e inchamento em espessura. As propriedades mecânicas apresentam relação linear crescente com o aumento do teor de resina, e decrescente com a porcentagem de associação de casca de café. Do modo que a pesquisa foi conduzida, a incorporação da casca de café prejudica a qualidade dos painéis produzidos.
\end{abstract}

Termos para indexação: Casca-de-café, aglomerado, Eucalyptus urophylla.

\section{ABSTRACT}

The objective of this study was to evaluate the influence of the incorporation of Coffee husks in the production of particleboard with Eucalyptus urophylla S.T. Blake. The panels were produced incorporating $25 \%$, 50\%, and $75 \%$ of Coffee husks at three levels of resin phenol-formaldehyde $\left(6,9\right.$ and $12 \%$ ) and $1 \%$ of paraffin. The nominal density of the panels was $0.7 \mathrm{~g} / \mathrm{cm}^{3}$ and the cycle of pressing consisted in a pressure of $3.92 \mathrm{MPa}$ under a temperature of $180^{\circ} \mathrm{C}$ for 8 minutes. By the results it was possible to observe that the physical properties of the particleboard have a linear relationship decreasing with the increase in the level of resin, and increasing with the increase in the percentage of coffee husks, showing higher values of water absorption and thickness swelling. The mechanical properties show a linear relationship growing with the increase of resin level, and decreasing with a reduction the percentage of coffee husk association. The way that the search was conducted, the incorporation of the Coffee husks harms the quality of the panels produced.

Index terms: Coffee husks, particleboard, Eucalyptus urophylla.

(Recebido em 27 de fevereiro de 2009 e aprovado em 2 de outubro de 2009)

\section{INTRODUÇÃO}

Os painéis aglomerados surgiram na Alemanha, no inicio da década de 40, a fim de viabilizar o uso de resíduos de madeira, em função da dificuldade de obtenção de madeiras de boa qualidade para produção de painéis compensados, por causa do isolamento da Alemanha durante a Segunda Guerra Mundial. (Iwakiri, 2005).

Atualmente, os painéis aglomerados são largamente utilizados na construção civil e setor moveleiro. A princípio, esses painéis podem ser fabricados com qualquer material lignocelulósico que lhes confiram alta resistência mecânica e massa específica préestabelecida, já que a estrutura dos materiais lignocelulósicos é semelhante à da madeira. (Rowell et al., 2000).

No Brasil, no entanto, são utilizados preferencialmente cavacos de madeira de florestas plantadas. Porém, os materiais lignocelulósicos provenientes de fibras vegetais e resíduos agroindustriais vêm sendo estudados para a produção de painéis aglomerados, como, por exemplo, o bagaço de cana-de-açúcar, casca de arroz, sabugo de milho, casca de café, casca de coco, dentre outros.

A casca de café é um resíduo gerado em grande volume no Brasil, em função da sua posição de maior produtor mundial. Segundo dados do Instituto Brasileiro de Geografia e Estatística-IBGE (2008), espera-se uma produção, para 2008,

${ }^{1}$ Universidade Federal de Lavras/UFLA - Departamento de Ciências Florestais/DCF - Cx. P. 3037 - $37200-000$ - Lavras, MG rafael_farinassi@hotmail.com

2Universidade Federal de Lavras/UFLA - Lavras, MG 
de 2,7 milhões de toneladas. Desse volume, 45 a 55\% são transformados em resíduo (Kihel, 1985; Giomo, 2006).

A produção de painéis com aplicação de resíduos de diferentes origens, pode contribuir para o atendimento da demanda de painéis, promover a adequada disposição final de resíduos e gerar materiais que preservem os recursos naturais. Quanto às propriedades e qualidade dos painéis, muitos são os fatores que contribuem para as características do produto final. Dentre elas, destacam-se as inerentes à madeira (espécies, densidade, $\mathrm{pH}$, teor de umidade, extrativos, local de crescimento, idade e forma do tronco) e os inerentes ao processo (densidade dos painéis, razão de compactação, composição dos painéis, resina e parafina, dimensão e orientação das partículas, umidade das partículas, tempo de fechamento da prensa, temperatura de prensagem e pressão específica) (Maloney, 1993).

Diante disso, neste estudo, objetivou-se avaliar a influência da incorporação de casca de café nas propriedades de painéis aglomerados produzidos com a madeira de Eucalyptus urophylla S.T. Blake.

\section{MATERIAL E MÉTODOS}

\section{Obtenção da matéria-prima utilizada}

A casca de café foi adquirida junto ao Núcleo de Estudo e Pesquisa do Café (NEPECAFE), localizado no Campus da Universidade Federal de Lavras, Lavras - MG; e a madeira de Eucalyptus urophylla procedente da Fazenda Vazante, localizada no município de Paracatu, Estado de Minas Gerais, pertencente à Empresa Votorantin S.A.

\section{Delineamento Experimental}

A variação da porcentagem de casca de café associada à madeira de eucalipto e os teores de resina (\%) empregados, constam na Tabela 1.

Para atender aos objetivos propostos, foram confeccionados três painéis para cada tratamento (Tabela 1), com massa específica nominal de $0,70 \mathrm{~g} / \mathrm{cm}$, resina fenolformaldeído e $1 \%$ de parafina (base peso seco do material) para todos os tratamentos.

\section{Manufatura dos painéis}

As partículas de eucalipto e as de casca de café, foram geradas em um moinho martelo com uma peneira de abertura de $6 \mathrm{~mm}$, uniformizando assim, as dimensões das partículas dos dois tipos de materiais.

As partículas foram secas até o teor de umidade de $3 \%$ com base na massa seca. Para tanto, foi utilizada estufa com circulação de ar forçada, com temperatura variando entre 60 e $65^{\circ} \mathrm{C}$. Sendo realizada a retirada dos "finos" com a utilização de uma peneira vibratória com abertura de 20 mesh.
A resina e a parafina foram aplicadas ao material por meio de aspersão, em uma encoladeira do tipo tambor giratório. As partículas ao saírem do tambor foram conduzidas a uma caixa formadora de colchão com as dimensões de 480mm x 480mm.

O colchão foi submetido a uma pré-prensagem a frio, com o objetivo de dar uma melhor conformação, e posterior prensado à quente, com temperatura de $180^{\circ} \mathrm{C}$, pressão específica de 3,92 MPa e tempo de prensagem de 8 minutos.

\section{Confecção e acondicionamento dos corpos-de-prova}

Os corpos-de-prova foram confeccionados com o emprego de uma serra circular esquadrejadeira. Inicialmente, retirou-se cerca de $2 \mathrm{~cm}$ de cada extremidade dos painéis, e em seguida, foram retirados os corpos-de-prova, com suas dimensões de acordo com os ensaios a serem aplicados.

Para as propriedades físicas (Absorção de água e inchamento em espessura) foi empregada a norma ASTM D1037-93 (American society for testing and materialsASTM, 2002); e para as propriedades mecânicas (Módulos de ruptura e elasticidade na flexão estática) foi empregada a norma DIN 52362 (Normen Für Holzfaserplaten Spanplatten Sperrholz-DIN, 1982), e para ligação interna a norma D1037-93 (ASTM, 2002).

Os corpos-de-prova foram postos em câmara de climatização mantida à temperatura de $20 \pm 2{ }^{\circ} \mathrm{C}$ e umidade relativa de $65 \pm 5 \%$, até atingirem umidade de equilíbrio em torno de $12 \%$.

\section{RESULTADOS E DISCUSSÃO}

\section{Propriedades físicas dos painéis}

Foram avaliados a absorção de água e inchamento em espessura.

\section{Absorção de água}

De acordo com a análise de variância (Tabela 2), não houve variação significativa para a absorção de água após 2 horas, para os teores de resina, as porcentagens de substituição de madeira de eucalipto por casca de café e para a interação desses fatores. Para 24 horas de imersão, observou-se variação significativa para o teor de resina e para a interação entre teor de resina e porcentagem de incorporação de casca de café.

Os resultados apresentados para a análise de desdobramento (Tabelas 3 e 4) indicaram que quando analisados os níveis de resina em cada nível de porcentagem de casca de café, houve variação estatística significativa apenas para a associação com $25 \%$ de casca de café. Porém, quando analisadas as diferentes porcentagens de 
associação de casca de café em cada nível de resina, os painéis produzidos com $12 \%$ de resina apresentaram diferença estatística entre eles.

Pela análise da Figura 1, pode-se observar uma relação linear decrescente entre a absorção de água após 24 horas de imersão e a porcentagem de resina, enquanto para a incorporação com casca de café esta relação foi crescente, aumentando a absorção de água com o aumento da porcentagem de casca.

\section{Inchamento em espessura}

De acordo com a análise de variância (Tabela 5), houve variação significativa para os teores de resina e porcentagens de substituição por casca de café, para inchamento em espessura após 2 e 24 horas de imersão em água.

Observa-se (Figuras 2 e 3 ) que houve uma relação linear decrescente entre o inchamento em espessura e a porcentagem de resina utilizada, para duas e vinte e quatro horas. Enquanto para a porcentagem de incorporação de casca de café a relação foi linear crescente.

Apenas os painéis produzidos com $12 \%$ de resina atenderam aos requisitos da norma CS 236-66 (Commercial Standard-CS, 1968) para inchamento em espessura, após vinte e quatro horas, que estipula valores máximos de $25 \%$.

Observou-se que as propriedades físicas foram melhoradas quando aplicada maior porcentagem de resina, $\mathrm{e}$ que, uma maior absorção de água e inchamento em espessura foi observada, a medida que se aumentou a porcentagem de associação de casca de café. Assim, a interação da casca do café que apresenta densidade básica de $0,195 \mathrm{~g} / \mathrm{cm}^{3} \mathrm{com}$ a madeira de eucalipto que apresenta densidade básica de $0,56 \mathrm{~g} / \mathrm{cm}^{3}$ precisa ser melhor entendida para se manipular as variáveis do processo, com o objetivo de melhorar as propriedades dos painéis produzidos. Esse fato se torna necessário, uma vez que um aumento no teor de resina pode inviabilizar a produção, em função do aumento dos custos.

\section{Propriedades mecânicas}

Foram avaliados os Módulos de Elasticidade (MOE) e de Ruptura (MOR) à flexão estática, a resistência a Compressão Paralela e a Ligação Interna.

\section{Flexão estática (MOE e MOR)}

De acordo com a análise de variância (Tabela 6), os Módulos de Ruptura (MOR) e de Elasticidade (MOE) à flexão estática, apresentaram variação significativa apenas para as porcentagens de substituição da madeira por casca de café.

Observa-se, na Figura 4, uma relação linear decrescente entre a porcentagem de incorporação de casca de café e os Módulos de Ruptura e Elasticidade na flexão estática. Em nenhuma das porcentagens de incorporação de casca de café, os valores de MOR e MOE atenderam aos requisitos da norma CS 236-66 (CS, 1968), que estipula valores mínimos de 17,16 e 3089,10 MPa, respectivamente.

\section{Compressão paralela e ligação interna}

De acordo com a análise de variância (Tabela 7), para a ligação interna houve variação significativa para o teor de resina e para a porcentagem de incorporação de casca de café. Para a compressão, houve variação significativa apenas para a porcentagem de incorporação de casca de café.

Observar-se (Figura 5 e 6) que existe uma relação linear decrescente entre a porcentagem de incorporação de casca de café e a compressão paralela e ligação interna. Para a ligação interna, existe uma relação linear crescente com o teor de resina. Porém, os valores médios de ligação interna não atenderam aos requisitos da norma CS 236-66 (CS, 1968), que estipula valores mínimos de 0,41 MPa.

De maneira geral, as propriedades mecânicas foram melhoradas quando aplicada maior porcentagem de resina, sendo as propriedades diminuídas, conforme se aumentou a porcentagem de incorporação de casca de café.

Tabela 1 - Delineamento experimental

\begin{tabular}{ccc}
\hline \multicolumn{1}{c}{ Incorporações } & & \\
\hline Eucalyptus urophylla $(\%)$ & Casca de café $(\%)$ & Teor de Resina $(\%)$ \\
\hline 75 & 25 & 6 \\
75 & 25 & 9 \\
75 & 25 & 12 \\
50 & 50 & 6 \\
50 & 50 & 9 \\
50 & 50 & 12 \\
25 & 75 & 6 \\
25 & 75 & 9 \\
25 & 75 & 12 \\
\hline
\end{tabular}

Ciênc. agrotec., Lavras, v. 34, n. 3, p. 610-617, maio/jun., 2010 
Tabela 2 - Resumo das análises de variância para a absorção após duas (AA2h) e vinte e quatro horas (AA24h).

\begin{tabular}{cccc}
\hline \multirow{2}{*}{ Fontes de Variação } & Graus de & \multicolumn{2}{c}{ Quadrados Médios } \\
\cline { 3 - 4 } & Liberdade & AA2H & AA24H \\
\hline Resina $(\mathrm{R})$ & 2 & $202,85 \mathrm{NS}$ & $300,90 *$ \\
Café $(\mathrm{C})$ & 2 & $208,13 \mathrm{NS}$ & $74,62 \mathrm{NS}$ \\
$\mathrm{R} \times \mathrm{C}$ & 4 & $53,98 \mathrm{NS}$ & $211,46 *$ \\
Erro & 18 & 69,74 & 56,38 \\
\hline CV $(\%)$ & & 11,34 & 8,79 \\
\hline
\end{tabular}

* Significativo a 5\% de probabilidade; NS - Não significativo a 5\% de probabilidade.

Tabela 3 - Resumo da análise de desdobramento dos níveis de resina em cada nível da porcentagem de café para o teste de absorção de água a vinte e quatro horas (AA24H).

\begin{tabular}{ccc}
\hline Fontes de Variação & Graus de Liberdade & Quadrados Médios \\
\hline Resina em 25\% de café & 2 & $530,81 * *$ \\
Resina em 50\% de café & 2 & $96,55 \mathrm{NS}$ \\
Resina em 75\% de café & 2 & $96,47 \mathrm{NS}$ \\
Erro & 18 & 56,38 \\
\hline
\end{tabular}

** Significativo a $1 \%$ de probabilidade; NS - Não significativo a 5\% de probabilidade.

Tabela 4 - Resumo da análise de desdobramento dos níveis de café em cada nível da porcentagem de resina para o teste de absorção de água em vinte e quatro horas (AA24H).

\begin{tabular}{ccc}
\hline Fontes de Variação & Graus de Liberdade & Quadrados Médios \\
\hline Café em 6\% resina & 2 & $50,07 \mathrm{NS}$ \\
Café em 9\% resina & 2 & $28,04 \mathrm{NS}$ \\
Café em 12\% resina & 2 & $419,43 *$ \\
Erro & 18 & 56,38 \\
\hline
\end{tabular}

** Significativo a 1\% de probabilidade; NS - Não significativo a 5\% de probabilidade.
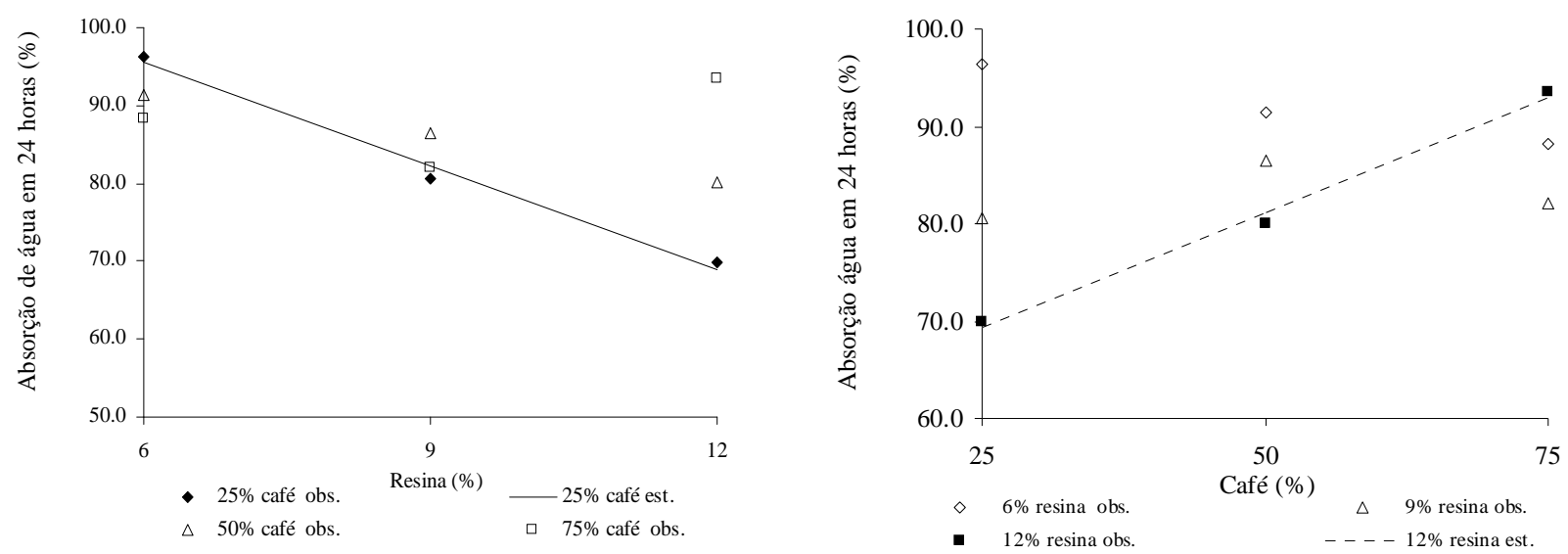

Figura 1 - Valores médios de absorção de água em vinte e quatro horas em função das porcentagens de resina, para cada porcentagem de substituição por casca de café (A) e das porcentagens de substituição por casca de café, para cada porcentagem de resina (B). 
Tabela 5 - Resumo das análises de variância para o teste de inchamento em espessura após duas (IE2h) e vinte e quatro horas (IE24h).

\begin{tabular}{cccc}
\hline \multirow{2}{*}{ Fonte de variação } & Graus de Liberdade & \multicolumn{2}{c}{ Quadrados Médios } \\
\cline { 3 - 4 } & 2 & IE2H & IE24H \\
\hline Resina $(\mathrm{R})$ & 2 & $366,57 * *$ & $527,34 * *$ \\
Café $(\mathrm{C})$ & 4 & $143,88 *$ & $188,40 *$ \\
R x C & 18 & $32,79 \mathrm{NS}$ & $34,80 \mathrm{NS}$ \\
Erro & & 19,73 & 33,70 \\
\hline CV $(\%)$ & 19,91 & 19,36 \\
\hline
\end{tabular}

* Significativo a 5\% de probabilidade; ** Significativo a 1\% de probabilidade; NS - Não significativo a 5\% de probabilidade.

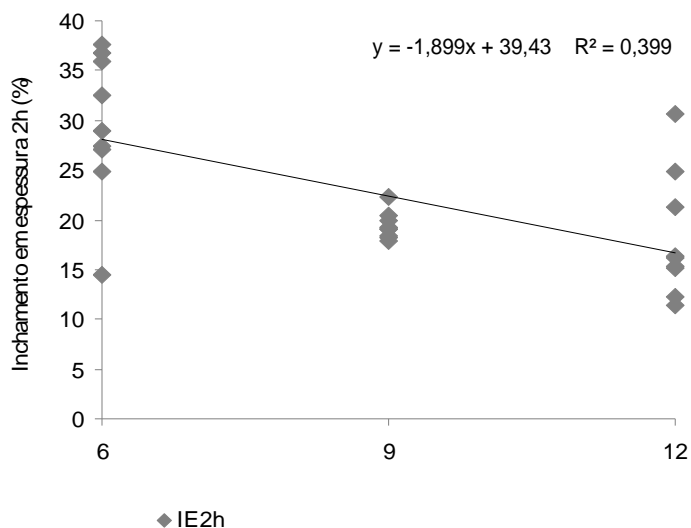

Resina (\%)

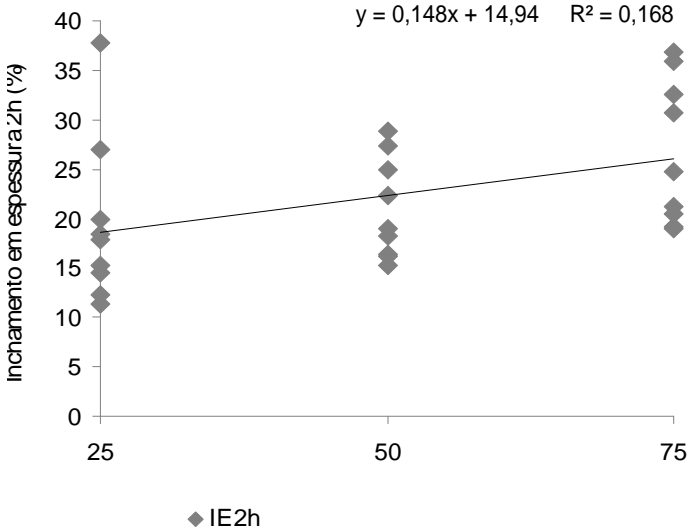

Café(\%)

Figura 2 - Valores médios de inchamento em espessura após duas horas.

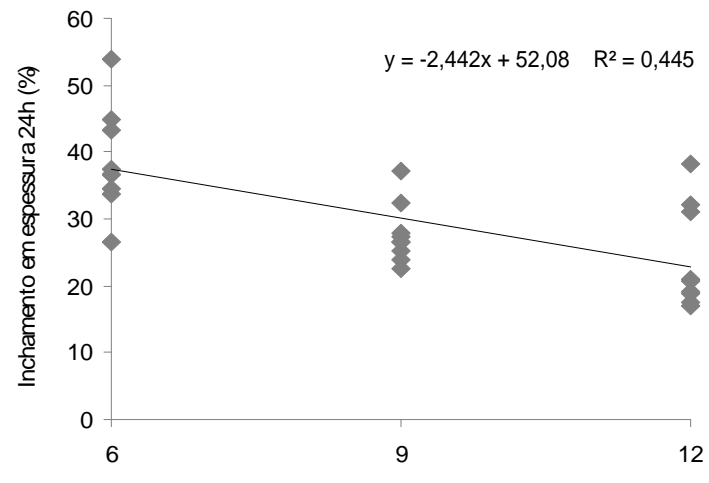

$\bullet$ IE24h

Resina (\%)

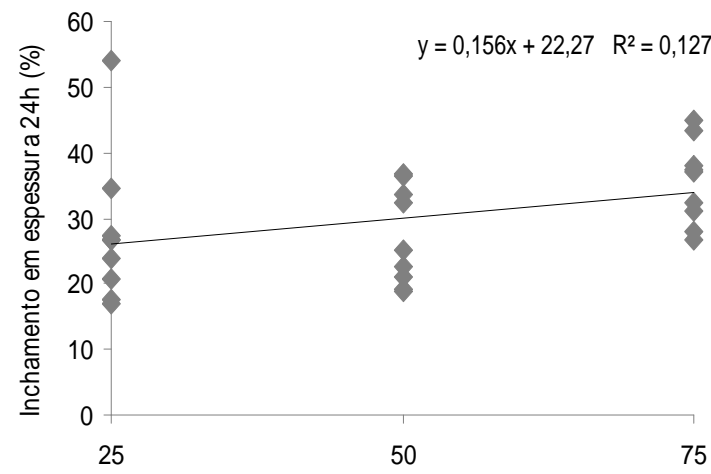

$\rightarrow$ IE24h

Café $(\%)$

Figura 3 - Valores médios de inchamento em espessura após vinte e quatro horas. 
Tabela 6 - Resumo das análises de variância para os Módulos de Ruptura (MOR) e de Elasticidade (MOE) à flexão estática.

\begin{tabular}{cccc}
\hline \multirow{2}{*}{ Fonte de variação } & Graus de & \multicolumn{2}{c}{ Quadrados Médios } \\
\cline { 3 - 4 } & Liberdade & MOR & MOE \\
\hline Resina (R) & 2 & $44,47 \mathrm{NS}$ & $2.884 .992,30 \mathrm{NS}$ \\
Café (C) & 2 & $484,05 * *$ & $50.887 .082,10 * *$ \\
R x C & 4 & $7,28 \mathrm{NS}$ & $251.637,20 \mathrm{NS}$ \\
Erro & 18 & 15,32 & $1.432 .798,10$ \\
\hline CV $(\%)$ & & 27,21 & 20,99 \\
\hline
\end{tabular}

** Significativo a $1 \%$ de probabilidade; NS - Não significativo a $5 \%$ de probabilidade.
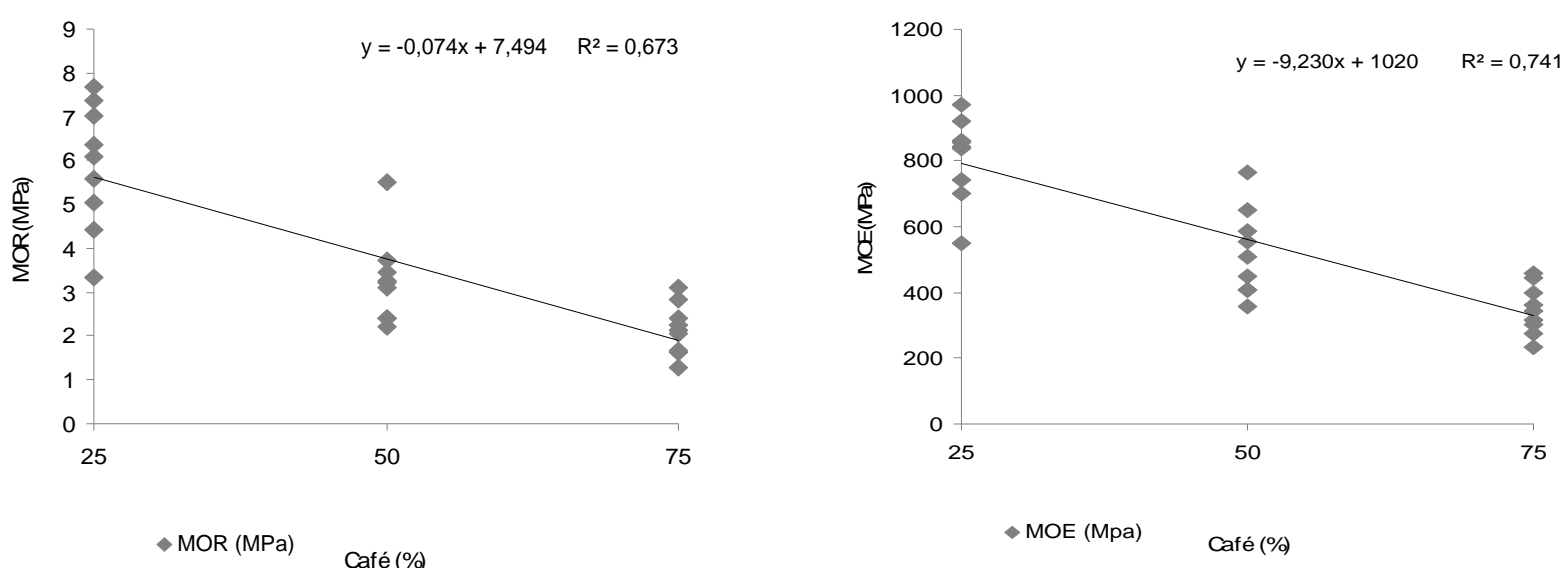

Figura 4 - Valores médios de módulo de ruptura e elasticidade na flexão estática.

Tabela 7 - Resumo das análises de variância para a compressão paralela (COMP) e ligação interna (LIG).

\begin{tabular}{cccc}
\hline \multirow{2}{*}{ Fonte de variação } & Graus de & \multicolumn{2}{c}{ Quadrado Médio (p-valor) } \\
\cline { 3 - 4 } & Liberdade & COMP & LIG \\
\hline Resina $(\mathrm{R})$ & 2 & $157,94 \mathrm{NS}$ & $0,96 * *$ \\
Café $(\mathrm{C})$ & 2 & $1.512,33 * *$ & $6,04 * *$ \\
R x C & 4 & $92,48 \mathrm{NS}$ & $0,12 \mathrm{NS}$ \\
Erro & 18 & 50,42 & 0,17 \\
\hline CV $(\%)$ & & 31,37 & 16,03 \\
\hline
\end{tabular}

** Significativo a $1 \%$ de probabilidade; NS - Não significativo a $5 \%$ de probabilidade. 


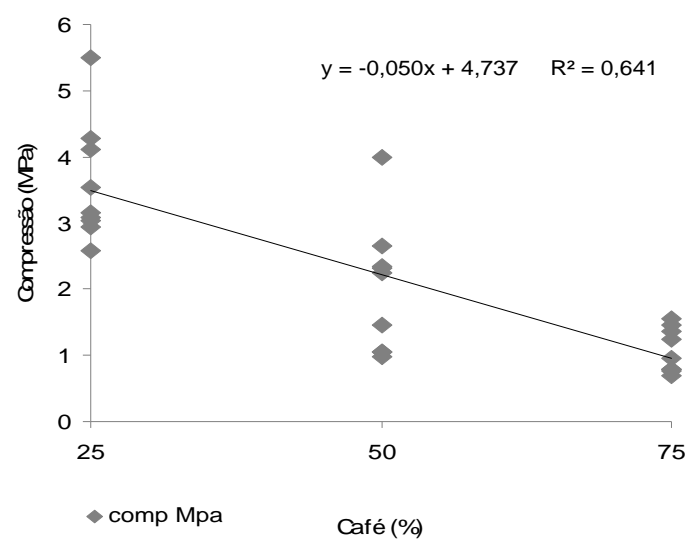

Figura 5 - Valores médios de compressão.
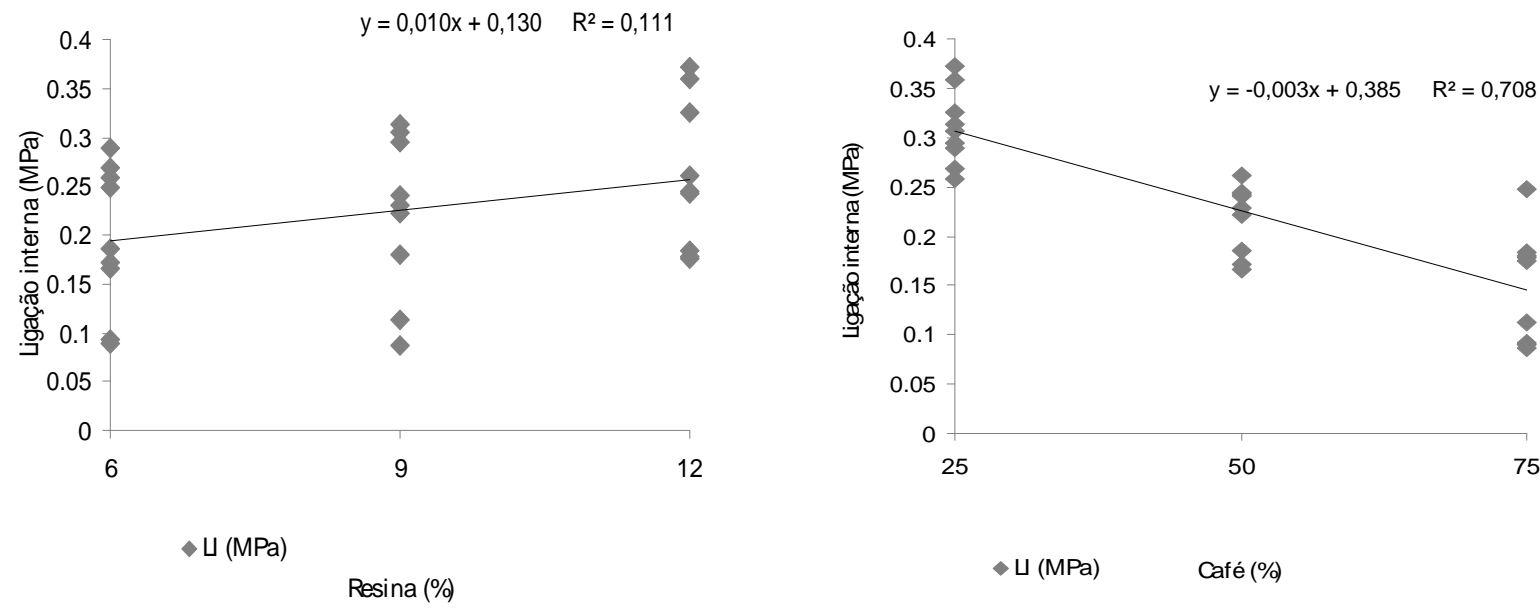

Figura 6 - Valores médios de ligação interna.

\section{CONCLUSÕES}

As propriedades físicas dos painéis aglomerados apresentam relação linear decrescente com o aumento do teor de resina, e crescente com a incorporação de casca de café, apresentando maiores valores de absorção de água e inchamento em espessura;

As propriedades mecânicas apresentam relação linear crescente com o aumento do teor de resina, e decrescente com a porcentagem de incorporação de casca de café.

Do modo que a pesquisa foi conduzida, a incorporação de casca de café prejudica a qualidade dos painéis produzidos.

\section{REFERÊNCIAS BIBLIOGRÁFICAS}

AMERICAN SOCIETY FOR TESTING AND MATERIALS. ASTM D-1037: standard methods of evaluating properties of wood-base fiber and particles materials. Philladelphia, 2002.

COMMERCIAL STANDARD. CS 236-66: mat formed wood particle board. [S.1.], 1968.

GIOMO, G.S. Informações eletrônicas. Campinas:

Instituto Agronômico de Campinas, 2006. 32p.

INSTITUTO BRASILEIRO DE GEOGRAFIA E ESTATÍSTICA. Anuário estatístico do Brasil. Rio de Janeiro, 2008. Disponível em: <http://Www.ibge.gov.br/ home/estatistica/economia/agropecuaria $\lambda$. Acesso em: 15 ago. 2008 .

IWAKIRI, S. Painéis de madeira reconstituída. Curitiba: UFPR, 2005. 121p. 
KIHEL, E.J. Fertilizantes orgânicos. Piracicaba: Agronômica Ceres, 1985. 492p.

MALONEY, T.M. Modern particleboard and dry process fiberboard manufacturing. 2.ed. São Francisco: M.Freeman, 1993. 689p.

NORMEN FÜR HOLZFASERPLATEN SPANPLATTEN SPERRHOLZ. DIN 52362. In: Testing of wood chipboards bending test, determination of bending strength. Berlin, 1982. p.39-40.

ROWELL, R.M.; HAN, J.S.; ROWELL, J.S.

Characterization and factors affecting fiber properties. In: FROLLINI, E.; LEÃO, A.L.; MATTOSO, L.H.C. (Eds.). Natural polymers and agrofibers based composites: section II, agrofibers composites. São Carlos: Embrapa Instrumentação Agropecuária, 2000. p.115-134. 